\title{
QUALIFICANDO OS PROCESSOS DE LEITURA E ESCRITA DOS ALUNOS EM UMA ESCOLA MUNICIPAL DE ARROIO GRANDE
}

\author{
CALIFICAR LOS PROCESOS DE ESCRITURA Y ESCRITURA DE \\ ESTUDIANTES EN UNA ESCUELA MUNICIPAL EN ARROIO GRANDE
}

\author{
QUALIFYING THE WRITING AND WRITING PROCESSES OF \\ STUDENTS AT A MUNICIPAL SCHOOL IN ARROIO GRANDE
}

\begin{abstract}
Sabrina Leal ${ }^{1}$
Resumo

Este projeto de Intervenção teve como desígnio criar, aplicar, descrever, e avaliar uma intervenção focada na formação do leitor, possibilitando a reflexão dos estudantes, por meio de Rodas de Leitura, propostas em sala de aula de Ensino Fundamental II, com uma turma de $8^{\circ}$ ano, da Rede Municipal do município de Arroio Grande RS. Após aplicada a intervenção, concluí que os questionamentos originaram um raciocínio mais aguçado na hora de pensar e organizar as ideias dos alunos para as respostas e para escritas de questionamentos. Também o contato do educando com a leitura desenvolveu nova perspectiva e conhecimento da realidade em que vivem antes privilégio de uma classe elitista econômica por ter acesso aos mais nobres recursos - pois estava agora aos acessos de quem antes não tinha o hábito de ler, por não terem tido oportunidade ou acesso à produção do conhecimento. A intervenção proporcionou a leitura em uma comunidade, antes empobrecidas de leitores, sem muito envolvimento com o mundo dos livros, para alguém que pudesse apaixonar-se pela prática cotidiana da leitura. Para a pesquisa realizei um processo de diagnóstico por meio de um questionário aberto para as professoras da área de linguagem, com quatro questões sobre o desenvolvimento dos processos de leitura e escrita dentro da sala de aula; um questionário misto, semiestruturado com dez perguntas fechadas e duas questões abertas, realizado com os alunos para identificar a percepção dos discentes sobre os processos de leitura e escrita. Esse procedimento induziu a reflexão profissional, cerne da pesquisa intervencionista (HATCHUEL, 2000), estabelecendo a união entre o conhecimento que surge da pesquisa e da experimentação na prática.
\end{abstract}

Palavras-Chave: Formação do Leitor, Rodas de Leituras, Pesquisa Intervencionista.

\section{Resumen}

Este proyecto de intervención tenía el propósito de crear, aplicar, describir y evaluar una intervención enfocada en la formación del lector, permitiendo a los estudiantes reflexionar, a través de Reading Wheels, propuesto en el aula de la Escuela Primaria II, con una clase de $8^{\circ}$ año, de la Red Municipal del municipio de Arroio Grande RS. Después de que se aplicó la intervención, llegué a la conclusión de que el cuestionamiento dio lugar a un razonamiento más agudo a la hora de pensar y organizar las ideas de los estudiantes para respuestas y para escribir preguntas. El contacto del estudiante con la lectura también desarrolló una nueva perspectiva y conocimiento de la realidad en la que vive, anteriormente el privilegio de una clase económica elitista por tener acceso a los recursos más nobles, ya que ahora era accesible para aquellos que anteriormente no tenían la costumbre de leer, por No he tenido la oportunidad o el acceso a la producción de conocimiento. La intervención proporcionó lectura en una comunidad, anteriormente empobrecida de lectores, sin mucha participación en el mundo de los libros, para alguien que podría enamorarse de la práctica diaria de la lectura. Para la investigación, realicé un proceso de diagnóstico a través de un cuestionario abierto para profesores de idiomas, con cuatro preguntas sobre el desarrollo de los procesos de lectura y escritura dentro del aula; Un cuestionario

\footnotetext{
${ }^{1}$ Graduada em Letras - Português pela Universidade Luterana do Brasil. E-mail: profeleal2016@gmail.com
} 
semiestructurado mixto con diez preguntas cerradas y dos preguntas abiertas, llevado a cabo con los estudiantes para identificar su percepción de los procesos de lectura y escritura. Este procedimiento indujo la reflexión profesional, en el corazón de la investigación intervencionista (HATCHUEL, 2000), estableciendo la unión entre el conocimiento que surge de la investigación y la experimentación en la práctica.

Palabras claves: Formação do Leitor, Rodas de Leituras, Investigación Intervencionista.

Abstract

This Intervention project had the purpose of creating, applying, describing, and evaluating an intervention focused on the formation of the reader, allowing students to reflect, through Reading Wheels, proposed in the Elementary School II classroom, with a class of students. 8th year, from the Municipal Network of the municipality of Arroio Grande - RS. After the intervention was applied, I concluded that the questioning gave rise to a sharper reasoning when thinking and organizing the students' ideas for the answers and for writing questions. The contact of the student with reading also developed a new perspective and knowledge of the reality in which they live - formerly the privilege of an elitist economic class for having access to the noblest resources since it was now accessible to those who previously were not in the habit of reading, for have not had the opportunity or access to knowledge production. The intervention provided reading in a community, previously impoverished of readers, without much involvement with the world of books, for someone who could fall in love with the daily practice of reading. For the research, I carried out a diagnostic process through an open questionnaire for language teachers, with four questions about the development of reading and writing processes within the classroom; a mixed, semi-structured questionnaire with ten closed questions and two open questions, carried out with the students to identify the students' perception of the reading and writing processes. This procedure induced professional reflection, at the heart of interventionist research (HATCHUEL, 2000), establishing the union between the knowledge that arises from research and experimentation in practice.

Key words: Reader formation, Reading wheels, Interventional research.

\section{INTRODUÇÃO}

Esse artigo tem por finalidade relatar o projeto de intervenção que teve como objetivo: Despertar nos alunos, do $8^{\circ}$ ano do Ensino Fundamental II, o gosto pela leitura e pela escrita por meio de Rodas de Leitura. Sobre isso, Silva (1991) indica que a leitura simboliza uma ação para que se possa produzir o saber, isso permite a percepção e a apreensão sobre as analogias que existem.

De acordo com Martins (1994), o aprendizado serve para produzir a ampliação de horizontes para o leitor, de maneira que ele possa compreender seu mundo e institua reações que possam gerar transformações. Consequentemente, a leitura e conhecimento são considerados por Martins (1994) processos interventivos de progressos para suas vidas. No que lhe diz respeito, a coletividade procurar informação através da leitura envolve localizar um embasamento sustentável para o desenvolvimento social.

Bakhtin (2002) também destaca a seriedade da leitura indissociada do social. Portanto, o intercâmbio verbal entre pessoas, possibilitada por meio da utilização da língua pelo falante e concebe o princípio criador da linguagem e apresenta modo dialógico.

Que de acordo com Antunes (2003, p.45), é considerada uma "ação entre", dessa maneira, o que um indivíduo executa ou pondera, está sujeito ao pensar do outro, originando uma analogia na qual "a iniciativa de um é regulada pelas ações do outro". 
De tal modo, que o uso ativo da linguagem deve acatar as precisões individuais, geradas conforme as demandas sociais de cada período ou circunstância. Pois é na influência mútua que se localiza a categoria de alargamento da linguagem, onde o indivíduo ajusta-se ao sistema linguístico.

Não se pode mais idealizar a elocução exclusivamente como representação do pensamento muito menos como maneira de comunicação, uma vez que para Bakhtin (1979), a linguagem é uma maneira de interação social que se constitui entre sujeitos socialmente instituídos e fixados em uma circunstância sólida de diálogo.

Dessa maneira, a leitura serve como um elemento de interação, em que o interlocutor toma um ambiente de sujeito ativo na construção do sentido e da língua pronuncia o linguístico, o social e o ideológico. Para Bakhtin (1979, p.79): “a palavra é o modo mais puro e sensível de relação social (...). É, justamente, na palavra que o mais perfeito se manifesta de maneiras básicas, as formas ideológicas gerais da comunicação (...)”.

Ao implantar no conjunto social a enunciação, Bakhtin especifica o adequado valor da língua, ou seja, sua realidade essencial, composta pelo "fenômeno social da interação verbal", que proporciona as situações para o desenvolvimento autêntico da língua: "a língua vive e evolui historicamente na comunicação verbal concreta" (BAKHTIN, 1979, p. 110).

Em nosso país, o desenvolvimento da leitura apresentou mais destaque após a publicação dos Parâmetros Curriculares Nacionais Brasil (1998), "referencial de qualidade para a educação no Ensino Fundamental em todo o país", que sugere a utilização de textos e dos vários gêneros textuais como componentes de ensino da linguagem verbal.

Dessa forma, por intermédio dos PCNs, a compreensão de linguagem como maneira de influência mútua é imediatamente manifestada e se entretém as considerações teóricas bakhtinianas que convêm na arena do ensino da leitura e da escrita, principalmente quando dirigidos para a produção do texto escrito acomodado a distintas circunstâncias comunicativas.

Portanto, a leitura e a escrita são práticas que se arrolam e se completam, os educandos são ledores em formação, esses processos deverão estar vinculados aos métodos de leitura que são ampliadas na escola. Dessa forma, a leitura e a escrita abrangem metodologias indissociáveis na prática discursiva, em que ler é um procedimento de cultivo de conhecimentos, a relevância de observar a leitura como prática social.

Optei por essa temática, porque vivencio essa problemática em sala de aula, onde os estudantes demonstram pouca afinidade com a Leitura e a Escrita, e uma enorme lacuna para produzirem textos com coerência e coesão. 
Relato que algumas das dificuldades dos processos de Produção Textual encontrados por mim em minha prática como docente das Áreas de Linguagens são as que envolvem o vocabulário empobrecido, carregado de gírias que os estudantes apresentam em suas produções, como o pouco domínio da língua culta, evidenciam as dificuldades de expressar suas ideias no papel, pois os alunos consideram o aspecto quantitativo ao invés do qualitativo para elaborarem suas escritas.

Por ser professora de Português e Produção Textual, percebo com mais intensidade a aversão dos alunos por qualquer atividade que abranja o ato de ler, pois os discentes, em sua grande maioria, apresentam textos precários e uma grande desmotivação em relação à leitura e a escrita, dessa maneira penso que haja necessidade de se trabalhar diferentes formas de aproximar os alunos de atividades que promoveram a Leitura e Escrita dentro da sala de aula.

Com essa intervenção organizei ações que despertassem o interesse dos alunos por essa temática, dentro das ações desenvolvidas, foram realizadas rodas de conversas com pessoas da comunidade que já possuem uma vasta trajetória nesse assunto, em que enfatizam em suas produções a preocupação em apresentar o livro para formar mais leitores.

A seguir apresento o capítulo de Fundamentação Teórica, que acredito estar associados com essa temática, composto por três seções sendo que na primeira seção, trato sobre a Leitura e a Escrita.

Na segunda seção, apresento de maneira breve o percurso da Literatura Infantojuvenil, destacando a importância dos livros para esse público. Enquanto que na terceira seção destaco a Formação do Leitor, abordando sua importância.

$\mathrm{Na}$ sequência, exponho os procedimentos metodológicos, esses foram desenvolvidos em duas etapas, comecei descrevendo a forma como a intervenção foi realizada, onde aponto as particularidades de um mestrado profissional, da Intervenção pedagógica e do seu enfoque qualitativo, listando como um dos instrumentos de coleta de dados empregado o questionário. Em seguida, trago o contexto e os sujeitos da Intervenção, sendo que ela ocorreu em uma escola Municipal, de Ensino Fundamental II, com uma turma de educandos do $8^{\circ}$ ano.

E na segunda etapa, descrevo como foi realizada a avaliação dessa intervenção, trazendo a descrição das ações que foram desenvolvidas, apresentando um quadro com as atividades realizadas durante a intervenção e os resultados obtidos.

Por fim, apresento as considerações finais do trabalho, seguida pelas referências e apêndices, neste último, entre outras passagens, estão alguns dos materiais foram utilizados na Intervenção. 


\section{DESENVOLVIMENTO}

O mestrando é o ser atuante para efetuar transformações significativas no seu ambiente de trabalho, uma vez que, está em formação, se reciclando e aperfeiçoando sua prática, embasando-a nas teorias estudadas, conforme, Damiani (2003), assegurando que este tipo de pesquisa tem por desígnio a Intervenção no fazer pedagógico, para o avanço dos processos de ensino e de aprendizagem.

O Município de Arroio Grande foi iniciado no ano de 1803, por Manuel Jerônimo, provavelmente Manuel Jerônimo de Sousa, avô do Barão de Mauá.

A população estimada do município no ano de 2018 era de 18.351 habitantes, segundo dados do Instituto Brasileiro de Geografia e Estatística (IBGE)². O mapa abaixo mostra a localização da cidade no mapa do Rio Grande do Sul.

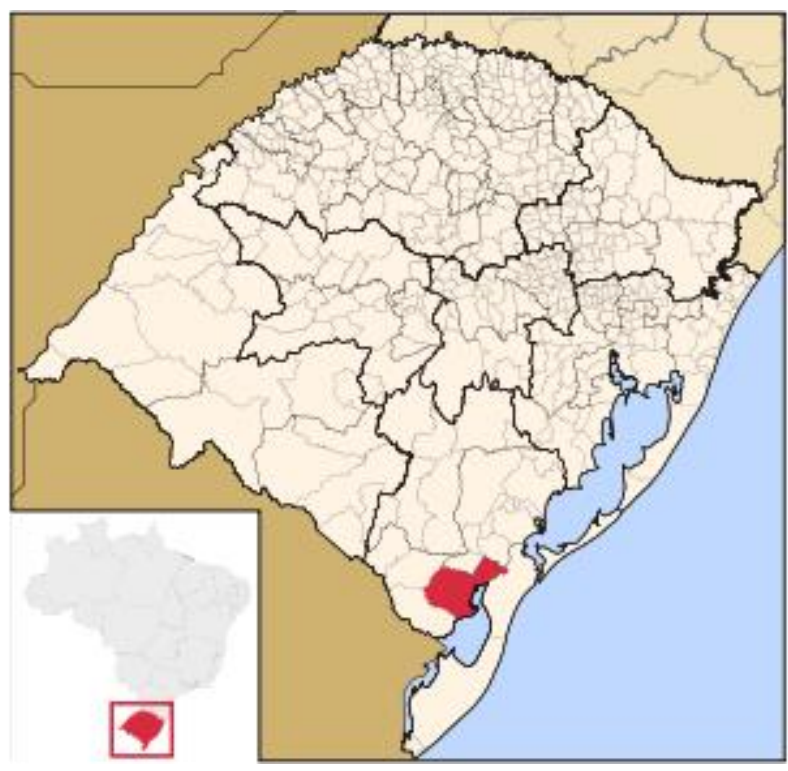

Figura 1 - Mapa da cidade de Arroio Grande. ${ }^{3}$

A pesquisa-intervenção aconteceu na Escola Municipal de Ensino Fundamental Presidente João Goulart, situada no Município de Arroio Grande, no extremo sul do Rio Grande do Sul. A cidade dispõe 08 educandários estaduais, 06 dessas de ensino fundamental e 02 de ensino médio (uma na modalidade regular e outra na modalidade EJA) e a rede municipal disponibiliza 05 escolas de ensino fundamental apresentando, também, turmas de pré-escolar (duas estão localizadas na zona rural). O educandário em que a pesquisa foi concretizada tem um diferencial em relação ao atendimento dos discentes nos dois turnos, isso

\footnotetext{
2 Dados sobre a população da cidade disponível em: http://cidades.ibge.gov.br/xtras/perfil.php?lang=\&codmun=430130\&search=rio-grande-do-sul|arroio-grande acesso em 05 de agosto de 2019.

3 Disponível em: http://cidades.ibge.gov.br/xtras/perfil.php?lang=\&codmun=430130\&search=rio-grande-dosul|arroio-grande. Acesso em 05 de agosto de 2019
} 
permite que haja alunos matriculados do pré-escolar ao $9^{\circ}$ ano do ensino fundamental, pela manhã e no turno da tarde.

A Escola Municipal de Ensino Fundamental Presidente João Goulart, campo de pesquisa, está situada na Avenida da Saudade, número 433, no bairro Branco Araújo, no Município de Arroio Grande.

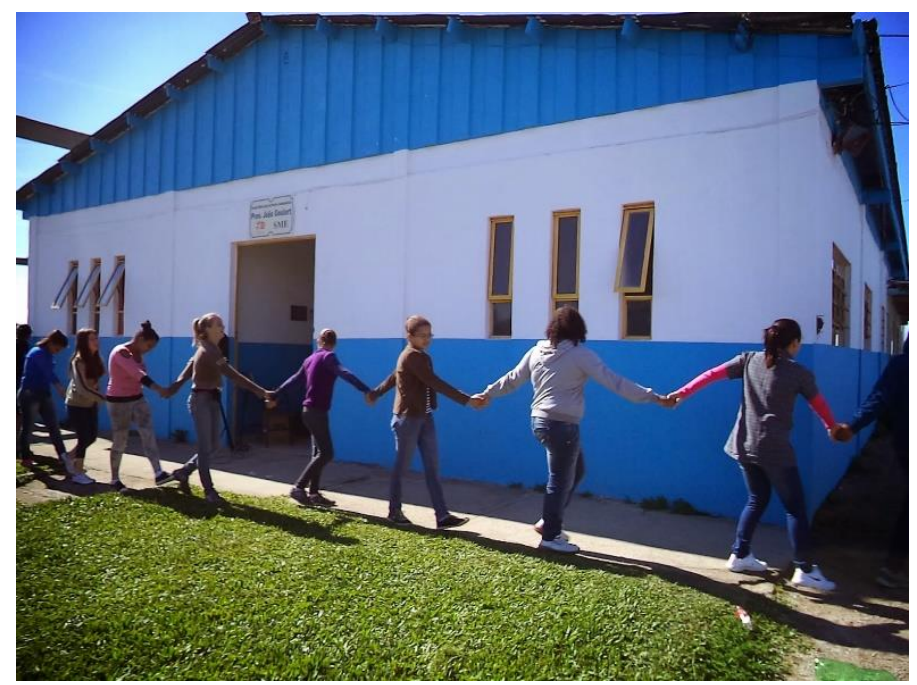

Figura 2 - Imagem da frente da Escola Municipal de Ensino Fundamental Presidente João Goulart. ${ }^{4}$

Em 2018, este Educandário contava com 383 alunos matriculados, e divididos nos turnos manhã e tarde, com o funcionamento da Educação Infantil ao $9^{\circ}$ ano do Ensino Fundamental em ambos os turnos. Os sujeitos atendidos, em sua maioria, são de família de classe econômica médio-baixa.

A Escola possui quarenta e sete professores, oito funcionários e seis monitores. Além de atender alunos do bairro Branco Araújo, também estão matriculados estudantes de todos os outros bairros da cidade e, também como, os vindos da zona rural que utilizam o transporte escolar.

A tabela 2 exibe, de maneira detalhada, a quantidade de discentes por ano, do turno da manhã.

\footnotetext{
${ }^{4}$ Disponível em: http://imprensaarroiogrande.blogspot.com/2014/10/15-anos.html Acesso em 30 de junho de 2018.
} 
RELACult - Revista Latino-Americana de Estudos em Cultura e Sociedade

Revista Latinoamericana de Estudios en Cultura y Sociedad | Latin American Journal of Studies in Culture and Society V. 06, Edição Especial, out., 2020, artigo no 1878| claec.org/relacult | e-ISSN: 2525-7870

Tabela 1 - Matrícula de alunos da escola no ano de 2018. Fonte: Produzido pela pesquisadora. (2018)

\begin{tabular}{|c|c|c|c|}
\hline Ano & $\begin{array}{c}\text { Quantidades } \\
\text { de Turmas }\end{array}$ & Turno & Número de alunos \\
\hline $\begin{array}{c}\text { Educação } \\
\text { Infantil }\end{array}$ & 2 & Manhã / Tarde & 37 \\
\hline $1^{\mathbf{0}}$ ano & 2 & Manhã / Tarde & 40 \\
\hline $2^{\mathbf{0}}$ ano & 2 & Manhã / Tarde & 40 \\
\hline $3^{\mathbf{0}}$ ano & 2 & Manhã / Tarde & 37 \\
\hline $4^{\mathbf{0}}$ ano & 2 & Manhã / Tarde & 56 \\
\hline $5^{\mathbf{0}}$ ano & 3 & Manhã / Tarde & 42 \\
\hline $6^{\mathbf{0}}$ ano & 2 & Manhã / Tarde & 41 \\
\hline $7^{\mathbf{0}}$ ano & 2 & Manhã / Tarde & 48 \\
\hline $8^{\mathbf{0}}$ ano & 2 & Manhã / Tarde & 30 \\
\hline $9^{\mathbf{0}}$ ano & 2 & Manhã / Tarde & \\
\hline
\end{tabular}

Durante o ano de 2018, a Escola apresentava vinte e duas turmas, distribuídas em doze salas, uma sala de recursos improvisada, um refeitório, uma sala de informática, uma biblioteca em parte do corredor (sem acesso ao aluno), o recinto escolar é extenso: dispõe de quatro prédios espalhados no terreno, contendo salas de aula, cozinha, refeitório e banheiro. As edificações não são todas integrada há espaços entre elas, nem todos esses lugares são cobertos. O pátio é amplo e não é completamente fechado, o que proporciona o ingresso de pessoas estranhas no ambiente escolar, assim como de animais, como: cachorros e cavalos. Outros recintos $^{5}$ da escola são: as salas de aulas, sala de recursos multifuncional, que trabalha em caráter de improviso ao final de um dos corredores e a biblioteca que, está situada num outro espaço do corredor, sala de direção, orientação pedagógica, coordenação e secretaria, ambas dividindo a mesma sala.

Este estabelecimento é composto por uma diretora, uma vice-diretora, três coordenadores pedagógicos, uma orientadora educacional, uma secretaria, um inspetor de disciplina, três cozinheiros, três serventes, uma bibliotecária, duas professoras de educação

\footnotetext{
${ }^{5}$ Os problemas de estrutura física da escola estão relacionados a um sinistro que ocorreu no ano de 2016 destruindo 04 salas de aula, a sala de informática, a sala de recursos multifuncional, a sala da direção e um sanitário, sendo necessária a adequação do espaço que já possuía para suprir as necessidades, sendo assim este educandário está funcionando com seus espaços limitados. A obra de reconstrução dos espaços destruídos no sinistro começou no início de 2018.
} 
especial, cinco monitores, um zelador e quarenta e sete professores. A JG, como é carinhosamente conhecida, apresenta como característica comum abraçar a inclusão, já que possuí alunos incluídos em todos os anos.

A avaliação é pensada como um processo contínuo, no qual a Educação Infantil, $1^{\circ} \mathrm{e}$ $2^{\circ}$ anos avançam para ao ano posterior, do $3^{\circ}$ ao $9^{\circ}$ ano é obrigatória a soma de 60 pontos ao final dos três trimestres para a aprovação que é distribuída da seguinte forma, I e II trimestres tem peso 30 pontos, cada um, e o III o valor de 40 pontos.

Como leciono com alunos de $7^{\circ}$ ao $9^{\circ}$ ano do Ensino Fundamental II da referida escola campo de pesquisa, inicialmente identifiquei que houvesse necessidade de refinar o grupo pesquisado, então preferi apenas uma turma, haja vista, que trabalho com quatro turmas, sob minha responsabilidade são aproximadamente cem estudantes, e este seria um número inviável para desenvolver essa Intervenção.

Escolhi a turma de $8^{\circ}$ ano do turno da manhã para desenvolver minha intervenção, pois o referido grupo é formado por adolescentes, com interesses muitos distintos, pois nessa turma alguns alunos estão repetindo o $8^{\circ}$ ano e outros não, o que ocasiona uma certa distorção idade / série (ano), pela possibilidade de poder dar continuidade nesse trabalho no próximo ano, dessa maneira, a intervenção acarreta uma intenção para fortalecer a leitura e a formação do leitor em sala de aula, e para que os alunos se descubram leitores.

Então, para realizar a intervenção no educandário, inicialmente, fiz contato com os pesquisados para explicar como seria organizada a intervenção.

Minha Intervenção Pedagógica abrangeu dezesseis estudantes do Ensino Fundamental II, dentro das disciplinas de Português e Produção Textual, abrangendo alunos dentro da faixa etária em torno de 13 a 14 anos de idade. O grupo era composto por dez meninas e seis meninos, que compõem a turma do $8^{\circ}$ ano do turno da manhã da escola João Goulart.

Metodologicamente, trata-se de uma pesquisa intervencionista (HATCHUEL, 2000), de um processo constituído de ação, no qual não há isolamento entre o ato de pesquisar e o campo a ser pesquisado.

Portanto, trata-se de um tipo de pesquisa de intervenção pedagógica fazendo uma conexão entre a teoria e a prática, como abordam Rufino e Miranda (2007), para que, através da Intervenção, possamos trazer boas influências ao nosso ambiente escolar. "De acordo com esses princípios busca-se não apenas compreender o fenômeno, mas, também, identificar alternativas intervencionistas para sua superação" (RUFINO; MIRANDA, 2007, p. 08).

Uma proposta dessa natureza é imprescindível logo após identificado uma problemática que necessite de apreciação, estudo, ações e avaliações. O docente é, ou 
precisaria ser, um perene pesquisador de ações pedagógicas, propor-se a suplantar os desafios do dia-a-dia na Escola.

Considerando pesquisa efetivada por docentes em performance e sobre a sua própria exercício pedagógico, Lüdke, da Cruz e Boing (2009, p 456) asseguram que a "possibilidade de um professor da educação básica realizar pesquisa é algo que vem suscitando significativo debate no meio universitário".

Para Lüdke, da Cruz e Boing (2001) apresentam como aspecto positivo desse tipo de pesquisa a preparação de conceitos reflexivos por parte do docente. Considerando os aspectos negativos, apontam a deficiência de preparo para a performance científica dos docentes.

Embora com limites e dificuldades, é incontestável a seriedade da pesquisa por parte dos docentes sobre suas próprias tarefas, sobre sua atuação docente para a produção de conhecimentos e assimilação de conceitos teóricos que justifiquem suas práticas pedagógicas, Conforme afirma André (2016), não existe uma única maneira de pesquisa apropriada para se ajuizar e repensar a ação pedagógica.

A pesquisa qualitativa, analisa e descreve a pesquisa em sua maneira complexa. de acordo com Oliveira (2009) apresenta um caráter hermenêutico, porque segue a regra na ação de examinar os experimentos vivenciados pelos humanos.

Assim como, tem confirmado Silveira e Córdova (2009, p 32) “(...) na pesquisa qualitativa, o cientista é ao mesmo tempo o sujeito e o objeto de suas pesquisas", pois ela não se empenha com a representatividade numérica, porém com o aperfeiçoamento da percepção de um grupo social ou de uma organização (GOLDENBERG, 1997). O desígnio da amostra qualitativa é produzir subsídios expostos, podendo ser pequena ou grande, porém que consista em ser capaz de construir novas informações (DESLAURIERS, 1991).

Para expandir este procedimento de análise é indispensável, focar na interpretação, porque esta proporciona a inclusão da realidade dos sujeitos emaranhados e foca na seriedade da flexibilidade do pesquisador no seu estilo de se administrar o estudo.

A importância de eu ter realizado essa intervenção se justifica, porque a partir do momento em que pude identificar situações insatisfatórias dentro do ambiente escolar no qual eu convivo, logo, busquei me abastecer de teorias para embasar minha pesquisa e apontar alternativas de melhoria ou, seja, edificar junto com o grupo de alunos, sugestões para superara a desmotivação dos alunos em relação à leitura.

O plano de ação que foi selecionado para o desenvolvimento da intervenção, consolidando a intenção de despertar, junto aos envolvidos no processo, o gosto pela Leitura e Escrita, na busca de formar novos leitores, através da realização de Rodas de Conversas, na 
perspectiva do trabalho colaborativo, entre docente e discentes, As percepções referentes as Relações entre a Leitura e a Escrita serão melhores esclarecidas no capítulo 5, através do Referência Teórico.

Apresento um quadro com os oito encontros da intervenção que foram preparados e dispostos, após o estudo dos dados coletados através dos questionários iniciais realizados com o grupo de professores da área de linguagem e outro efetivado com os discentes.

Os procedimentos da intervenção foram programados com a finalidade de motivar e formar leitores, conduzindo à avanços em relação aos processos de ensino e aprendizagem, assim como ressalta Damiani et al., (203, p. 58):

\footnotetext{
Antes de defender a adequação do uso do termo intervenção na área da Educação, pensamos ser necessário definir o que entendemos por pesquisa do tipo intervenção pedagógica. Segundo nossa concepção, são investigações que envolvem o planejamento e a implementação de interferências (mudanças, inovações) destinadas a produzir avanços, melhorias, nos processos de aprendizagem dos sujeitos que delas participam e a posterior avaliação dos efeitos destas interferências.
}

Após analisar o contexto desenvolvi oito Oficinas, para que a Intervenção pudesse ser finalizada antes de encerrar o ano letivo de 2018, essas ocorreram em dias de semana, nos períodos reservados para as aulas de Português e Produção Textual, observando assim, o objetivo geral do projeto que é qualificar os processos de Produção e Escrita dos discentes, possibilitando também meu crescimento e desenvolvimento profissional através dessa Intervenção.

Portanto, toda atividade racional é sistemática, e a pesquisa demanda que as ações desenvolvidas ao longo de seu processo sejam realmente planejadas. (GIL, 2002, p. 19), dessa forma apresento um quadro descrevendo as ações desenvolvidas, os objetivos de cada encontro, os suportes utilizados e os resultados esperados em cada um deles, logo a seguir descrevo as Oficinas da intervenção.

\subsection{Estruturas das Oficinas desenvolvidas na Intervenção}

Nesta etapa, exibo um quadro contendo as oito Oficinas que foram aplicadas. Os planos estão organizados de maneira a fornecer uma visão sobre as abordagens realizadas com os alunos.

Baseado nisso, na primeira Oficina da Intervenção, realizei uma roda de conversa com a turma apresentando e combinando os detalhes do Projeto; em seguida, os discentes responderam um questionário abordando os conhecimentos prévios que os alunos possuíam sobre a importância da leitura no nosso cotidiano, apresentei o vídeo "A menina que odiava 
livros", com o intuito de que eles percebessem que a leitura, mesmo contra a vontade, tem o poder de encantar e seduzir o leitor.

Na segunda Oficina da Intervenção, realizei uma Roda de conversa com o Prof ${ }^{\circ}$ Me. Ivan Nunes Gonçalves ${ }^{6}$, abordando o tema sobre a importância da leitura e da escrita, contando sua trajetória como autor de livros e também apresentou os seus livros já lançados.

$\mathrm{Na}$ terceira Oficina da Intervenção, realizei uma visita até a Biblioteca Pública Municipal de Arroio Grande, onde os alunos foram recebidos pela Bibliotecária Virgínia Borges $^{7}$, que apresentou o acervo literário, sugestões de leituras infanto-juvenis e algumas orientações a respeito da postura que os discentes deveriam ter dentro do ambiente da Biblioteca.

Os estudantes participaram de uma explanação sobre a importância da leitura em nossas vidas e também ouviram sobre a trajetória de vida que tornou a $\mathrm{Sr}^{\mathrm{a}}$. Virgínia Borges em bibliotecária, orientei os alunos para que a buscar uma literatura que os agradassem, depois que encontraram suas literaturas favoritas, realizaram um cadastro na Biblioteca, levando os livros escolhidos para casa.

Na quarta Oficina da Intervenção, os alunos já estavam com seus livros em mãos, e fomos para o pátio da Escola, onde cada um, encontrou o melhor local para realizar a sua leitura.

Na quinta Oficina da Intervenção, os estudantes continuaram na leitura do livro em sala de aula.

\footnotetext{
${ }^{6}$ Professor regente de classe da Rede Municipal de Educação de Arroio Grande, desde o ano de 1987. Atualmente é professor de Matemática da Escola Estadual de Ensino Fundamental Min. Francisco Brochado da Rocha e Coordenador Pedagógico da Escola Municipal de Ensino Fundamental Pres. João Goulart. Neste período 1987 a 1989, exerceu a Direção da Escola Municipal de Ensino Fundamental Visconde de Mauá e ? 1994 a 2007 a Presidência da Fundação Arroio-Grandense de Educação (FAGE). Licenciado em Ciências Físicas e Biológicas, Graduado em Matemática pela Universidade Católica de Pelotas, onde recebeu o Prêmio Dom Antônio Zattera, oferecido ao aluno classificado em 1.o Lugar no Curso de Ciências, Habilitação em Matemática. Professor Oficineiro, Palestrante, Conferencista nas áreas de Ciências, Matemática, Química e Motivação em diversos municípios da Zona Sul. Possui Especialização em Mídias na Educação, através do Instituto Federal de Educação, Ciências e Tecnologia Sul Rio-Grandense, IFSUL, Especialização em Educação Infantil, através da Universidade Castelo Branco, UCB-RJ, Especialização em Supervisão Escolar através da UNILAS e Mestrado em Educação em Ciências pelo Instituto Politécnico de Bragança, Portugal. No final de 2011 recebeu em Brasília o Prêmio Professores do Brasil, 5.a Edição, oferecido pelo Ministério da Educação, através do projeto. Um olhar para o lixo. Em 2012 recebeu o Prêmio Microsoft Educadores Inovadores (São Paulo) e o Prêmio Professores do Brasil, 6.a edição (Brasília), com o Projeto Alimentos, eis a questão. Em 2013, através da Fundação de Apoio ao Colégio Estadual Júlio de Castilhos participou como um dos autores do livro A construção cotidiana da docência no Ensino Médio e, neste mesmo ano, escreveu um artigo intitulado Alimentos, eis a questão!? para a Revista do Professor. Em 2014, como resultado de um projeto realizado por grupos de pesquisa da Universidade Federal de Santa Catarina, UFSC, do Instituto Federal Sul-Rio-Grandense (IFSUL) e da Universidade de Pelotas (UFPEL), com o apoio do Ministério da Educação deu origem ao livro Disseminação de Tecnologias Educacionais: Prêmio Professores do Brasil. Em 2014 lança seu primeiro livro infantil intitulado ?O menino que brincava com as palavras?. Em 2015 lança o segundo livro infantil, A poesia do brinquedo? e ganha pela terceira vez o Prêmio Professores do Brasil com o Projeto Matematicando, tô ligado!. No final do ano de 2015 é convidado para ser patrono da Feira do Livro de Arroio Grande. Em 2016, lança o livro, Tempo de criança. Em 2017 lança o livro A poesia na educação. Em 2018 lança o livro Coisas de Criança. Acesso em 04/06/2019, Informações coletadas do Lattes.

${ }^{7}$ Bibliotecária concursada do Município de Arroio Grande.
} 
$\mathrm{Na}$ sexta Oficina da Intervenção, reuni a turma em círculo, e um aluno por vez, apresentou seu livro aos demais colegas, assim como, relatou suas impressões sobre a obra.

$\mathrm{Na}$ sétima Oficina da Intervenção, realizamos uma aula-passeio até a Biblioteca da Unipampa, onde os discentes mantiveram contato com os acervos disponíveis, uma das bibliotecárias apresentou a maneira de como era realizada a catalogação dos livros e também explanou sobre a importância do hábito da leitura.

$\mathrm{Na}$ oitava Oficina da Intervenção, realizei uma roda de conversa sobre as ações desenvolvidas, onde os alunos comentaram sobre as atividades mais significativas, enumerando entre elas a aproximação e leitura do livro, assim como a visitação às Bibliotecas Municipal e da Unipampa. A grande maioria dos discentes afirmou que consideraram significativas as Oficinas desenvolvidas e que estaria disposto a dar continuidade no trabalho no próximo ano.

Todas as ações foram pensadas e planejadas para fomentar as ideias abordadas já por Bakhtin (1992), quando aborda que o processo linguístico é obra do intercâmbio social dos partícipes de uma circunstância de comunicação, resumindo, o sujeito constitui-se à medida que interage com o outro.

A seguir, destaco um quadro com a proposta das Oficinas que foram desenvolvidas durante a intervenção, este enumera a Oficina, a data que foi desenvolvida e a sua temática.

Tabela 2 - Temáticas desenvolvidas na intervenção Fonte: Material da pesquisadora. (2018)

\begin{tabular}{|c|c|c|}
\hline \multicolumn{3}{|c|}{ Propostas das oficinas que foram desenvolvidas na intervenção } \\
\hline \multirow{2}{*}{ OFICINA } & DATA & TEMÁTICA \\
\hline 1 & $12 / 11 / 2018$ & $\begin{array}{c}\text { Motivação dos alunos sobre a } \\
\text { importância da leitura e da escrita; } \\
\text { Formação do leitor; }\end{array}$ \\
\hline 2 & $13 / 11 / 2018$ & $\begin{array}{c}\text { Aproximação dos alunos do autor do } \\
\text { livro; }\end{array}$ \\
\hline 3 & $19 / 11 / 2018$ & $\begin{array}{c}\text { Ampliação de repertório literário; } \\
\text { Formação do leitor; }\end{array}$ \\
\hline 4 & $20 / 11 / 2018$ & $\begin{array}{c}\text { Fomentação do prazer pela leitura; } \\
\text { Formação do leitor; }\end{array}$ \\
\hline 5 & $22 / 11 / 2018$ & Fomentação do prazer pela leitura; \\
\hline
\end{tabular}




\begin{tabular}{|c|c|c|} 
& & Formação do leitor; \\
\hline 6 & $26 / 11 / 2018$ & $\begin{array}{c}\text { Estimulação da oralidade; } \\
\text { Formação do leitor; }\end{array}$ \\
\hline 7 & $27 / 11 / 2018$ & $\begin{array}{c}\text { Ampliação de repertório literário; } \\
\text { Formação do leitor; }\end{array}$ \\
\hline 8 & $29 / 11 / 2018$ & $\begin{array}{c}\text { Avaliação da intervenção; } \\
\text { Formação do leitor; }\end{array}$ \\
\hline
\end{tabular}

Através desses dados levantados com os professores, foi possível analisar que os alunos precisam ser desafiados pela leitura e o docente tem o poder para despertar a curiosidade e o prazer em ler e produzir bons textos por estes educandos, o propósito é aprender fazendo, partindo desse pressuposto é perceptível que minhas colegas das áreas de Linguagens também enfrentam as mesmas angústias do que eu, quando se trata de abordar os processos de Leitura e Produção Textual dos estudantes.

Enquanto que com os discentes apliquei um questionário semiaberto ${ }^{8}$, composto por dez questões fechadas de múltipla escolha e duas questões abertas para diagnosticar o perfil inicial dos alunos em relação a temática pesquisada.

Quando os alunos foram questionados sobre o conceito que possuíam de leitura, quase $71,5 \%$ da turma apontou como uma das maneiras de que se aprende algo, pois realizar uma leitura exige ir além do que está escrito e é diante da relação de vários níveis de conhecimento, como o conhecimento linguístico, o textual, e o conhecimento de mundo, dessa maneira o ledor alcança a construção do sentido do texto. É dessa forma que Paulo Freire (1989, p.13) emprega a reputada frase "a leitura do mundo precede sempre a leitura da palavra", considerando a relevância do entendimento do mundo para a compreensão dos estímulos das palavras.

\footnotetext{
${ }^{8}$ Apêndice 4
} 
Defınição de leitura (Para mim, a leitura é, acima de tudo): 14 respostas
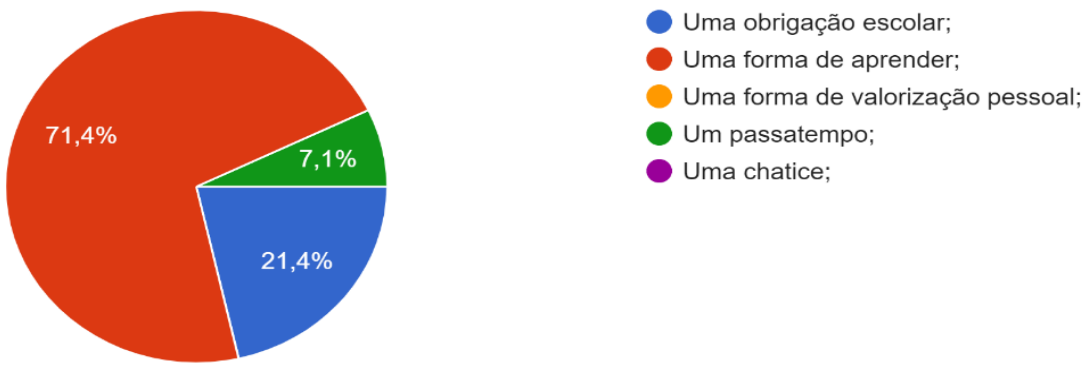

Gráfico 1: Definição de leitura dos alunos. Fonte: Material da pesquisadora. (2018)

Em contra partida, cerca de $21,5 \%$ percebe a leitura como uma obrigação escolar, enquanto que cerca de 7,5\% tem a leitura como um passatempo.

Quando os estudantes foram perguntados em relação ao suporte que utilizavam com mais frequência para realização de leituras, quase $86 \%$ da turma apontou que faziam uso de material digital, isso deve-se a chegada da Internet a um grande número de pessoas. Considerando, outras características do livro eletrônico, atingidas por meio dos aperfeiçoamentos tecnológicos, como formato, larga e rápida difusão de conteúdo e fácil distribuição, podendo possibilitar a difusão do livro. A internet pode ser uma grande parceira dos e-books e das etapas de universalização da leitura, ao proporcionar que o leitor compre um e-book em uma livraria virtual e leia-o sem sair de casa. O aumento da digitalização de livros de certa forma, deverá contribuir com a mudança do livro impresso para o digital e sua popularização. Como cita Procópio (2010, p. 25),

[...] a revolução dos eBooks possibilita democratizar o acesso à leitura a um nível ainda mais abrangente e de uma maneira extraordinária. Centenas de livros e documentos importantes, e muitas vezes dispersos, podem ser acessados com um simples clique.

Porém o e-book não apresenta só benefícios. Algumas inconveniências podem ser listadas. A perspectiva de observação e entendimento do leitor é um ponto relevante, pois a utilização do e-book está estritamente direcionada à sua preferência pessoal. Vários leitores optam por sentir a textura do papel, o cheiro, folhear as páginas, e isso e-book não pode oferecer.

E aproximadamente, 85,7\%, dos pesquisados tem acesso ao livro digital, por isso, por isso verifiquei a necessidade de incentivar e despertar o interesse dos alunos também para que tivessem contato com o livro impresso. 
Qual é o tipo de suporte que tu utilizas com mais frequência?

14 respostas

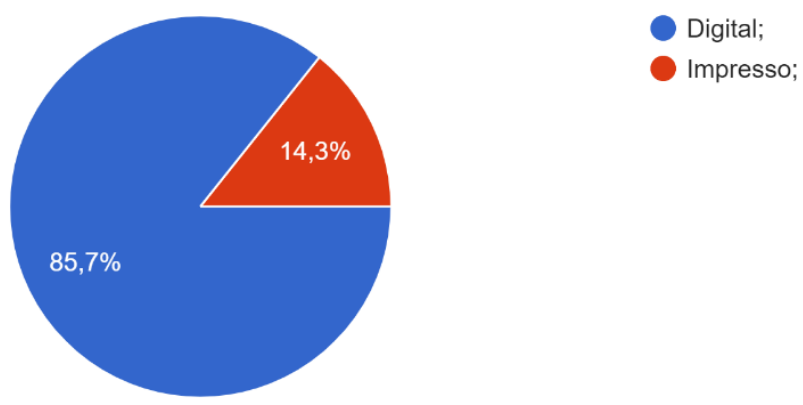

Gráfico 2 - Tipo de livro que os alunos leem. Fonte: Material da pesquisadora. (2018)

Quando os alunos foram questionados se haviam realizado a leitura de algum livro durante o ano de 2018, 50\% dos estudantes relataram ter realizado a leitura de mais de um livro no período questionado, no entanto quase $21,5 \%$ da turma afirmou ter realizado a leitura de pelo menos um livro no ano, enquanto que $29 \%$ pontuaram não terem realizado nenhuma leitura neste período, fato que me deixou muito preocupada, visto que esta é uma das habilidades cobradas por mim nas Disciplinas de Português e Produção Textual.

Neste ano, tu leste algum livro?

14 respostas

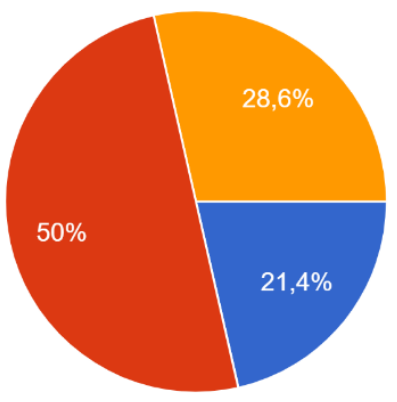

Sim, li um livro;

Sim, li mais de um livro;

Não li nenhum livro este ano.

Gráfico 3 - Indicativo de leitura anual dos alunos. Fonte: Material da pesquisadora. (2018)

Em relação aos gêneros textuais preferidos pelos estudantes, aproximadamente cerca de 65\% preferem o gênero aventura / ação, percebe-se que na faixa etária, entre 1213 anos, estão em fase de modificações socio cognitivas e comportamentais, e são naturalmente curiosas, fascinam-se por mistérios, aventuras, histórias cheias de ação. A hipótese que estou considerando é a que os discentes preferem essa tipologia, pelas peculiaridades do gênero. 
Que tipo de livros lês:

14 respostas

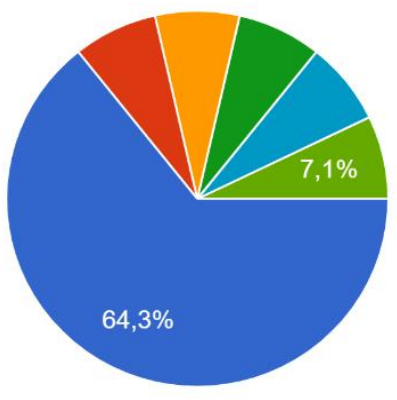

Aventura/ ação;

Ficção científica;

Histórias românticas;

Poesias;

Policiais;

Religiosos:

Autoajuda:

HQ e Manguás;

$1 / 2 \nabla$

Gráfico 4 - Tipo de livro que os alunos leem. Fonte: Material da pesquisadora. (2018)

Enquanto que os demais discentes apontaram interesse nos gêneros de ficção científica, histórias românticas, poesias, HQ e manguás, ambos os gêneros com pontuação de cerca de $7 \%$ cada um.

Quando os discentes foram questionados se gostavam de escrever, cerca de 71,5\% responderam que não gostam de escrever, e somente 29\% relataram que gostam de escrever; para os que gostam de escrever foi questionado sobre o que escreviam, as respostas foram variadas, destacando-se temáticas como: ficção científica, vivências experienciadas por eles e poesias, conforme o registro abaixo.

\section{Tu gostas de escrever?}

14 respostas

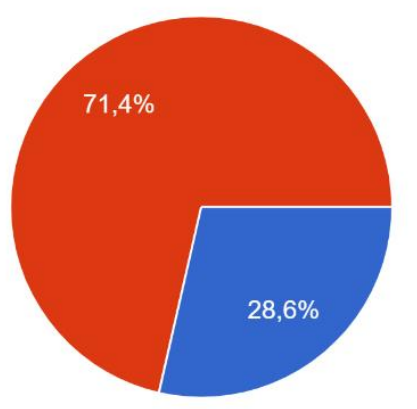

Gráfico 5 - Porcentagem de alunos que gostam de escrever. Fonte: Material da pesquisadora. (2018)

Quando os alunos foram questionados se conheciam algum autor de livro, cerca de 57\% dos pesquisados afirmaram conhecer um escritor, e apontaram o Professor Mestre Ivan Nunes Gonçalves 
Conheces, pessoalmente, algum autor de livro?

14 respostas

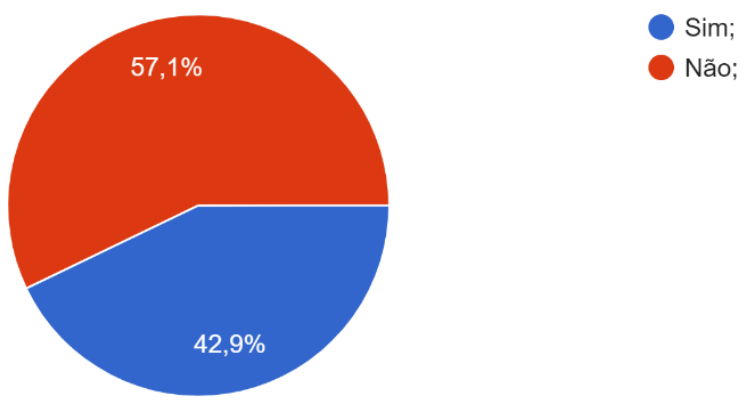

Gráfico 6 - Porcentagem de alunos que já conheceram um autor. Fonte: Material da pesquisadora. (2018)

Quando os alunos foram questionados se já haviam pensado em escrever algum livro, cerca de $79 \%$ responderam que não e apenas $21,5 \%$ confirmaram já terem pensado em escrever, mostrando interesse pela escrita.

Já pensaste em escrever algum livro?

14 respostas

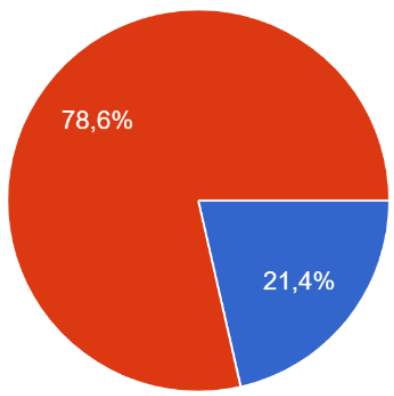

Gráfico 7 - Porcentagem de alunos que já pensaram em escrever um livro. Fonte: Material da pesquisadora.

(2018)

Quando questionados sobre os filmes que mais gostavam de assistir, os gêneros mais pontuados foram de ação e os de comédia. 
RELACult - Revista Latino-Americana de Estudos em Cultura e Sociedade

Revista Latinoamericana de Estudios en Cultura y Sociedad | Latin American Journal of Studies in Culture and Society V. 06, Edição Especial, out., 2020, artigo n ${ }^{\circ}$ 1878| claec.org/relacult | e-ISSN: 2525-7870

Qual é o gênero de filme que mais gostas?

14 respostas
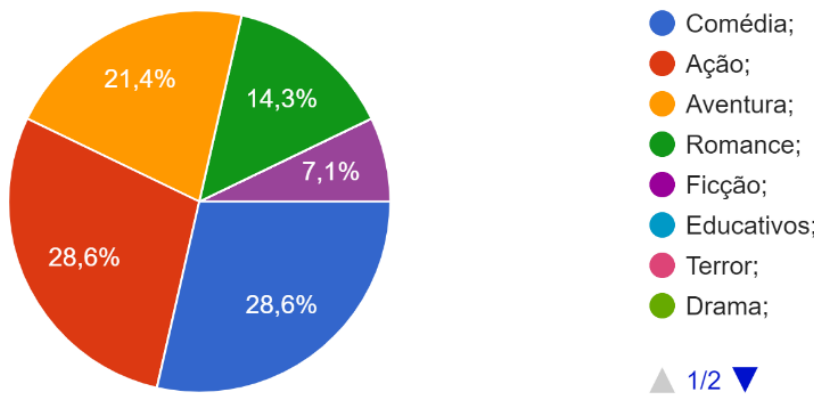

Gráfico 8 - Gênero de filme favorito. Fonte: Material da pesquisadora. (2018)

Em relação ao estilo musical, os alunos relataram gostarem mais do ritmo sertanejo.

\title{
Que estilo musical costumas ouvir?
}

\author{
14 respostas
}

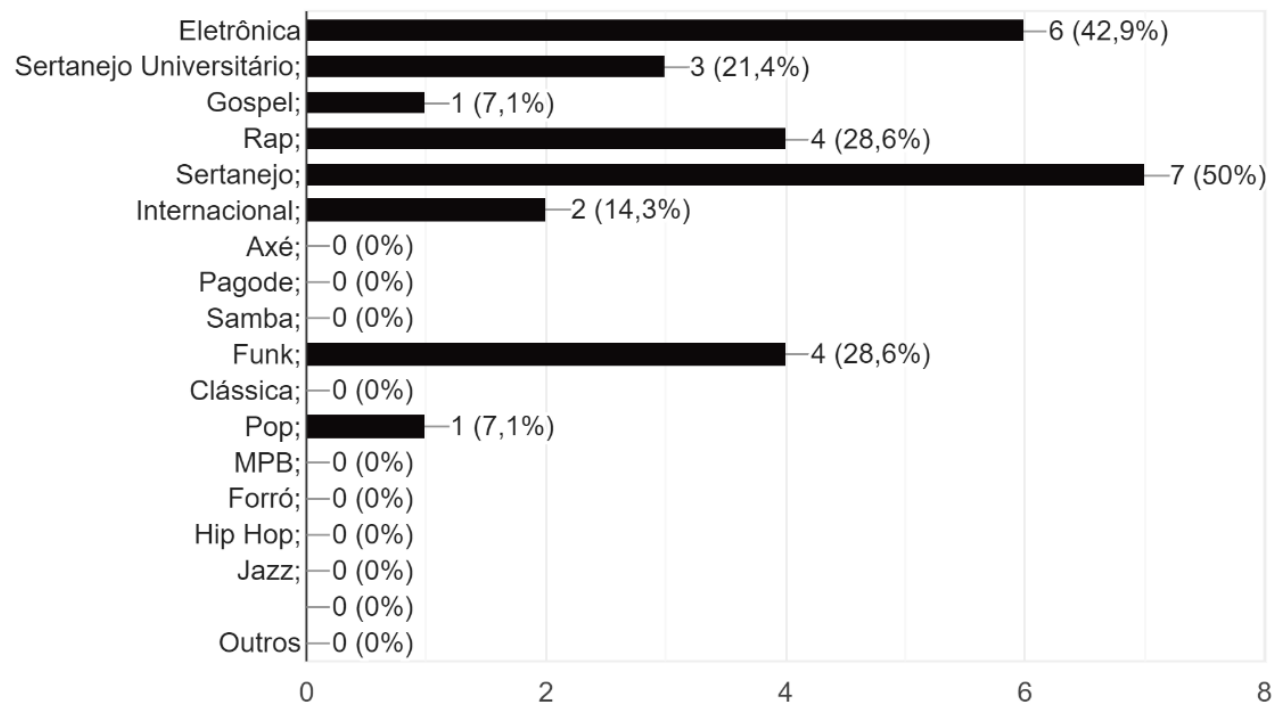

Gráfico 9 - Estilos musicais dos alunos. Fonte: Material da pesquisadora. (2018)

Em relação as pesquisas nos websites, os alunos relataram passar muito tempo no Facebook. 
Que tipo de websites acessas com mais frequência?

14 respostas

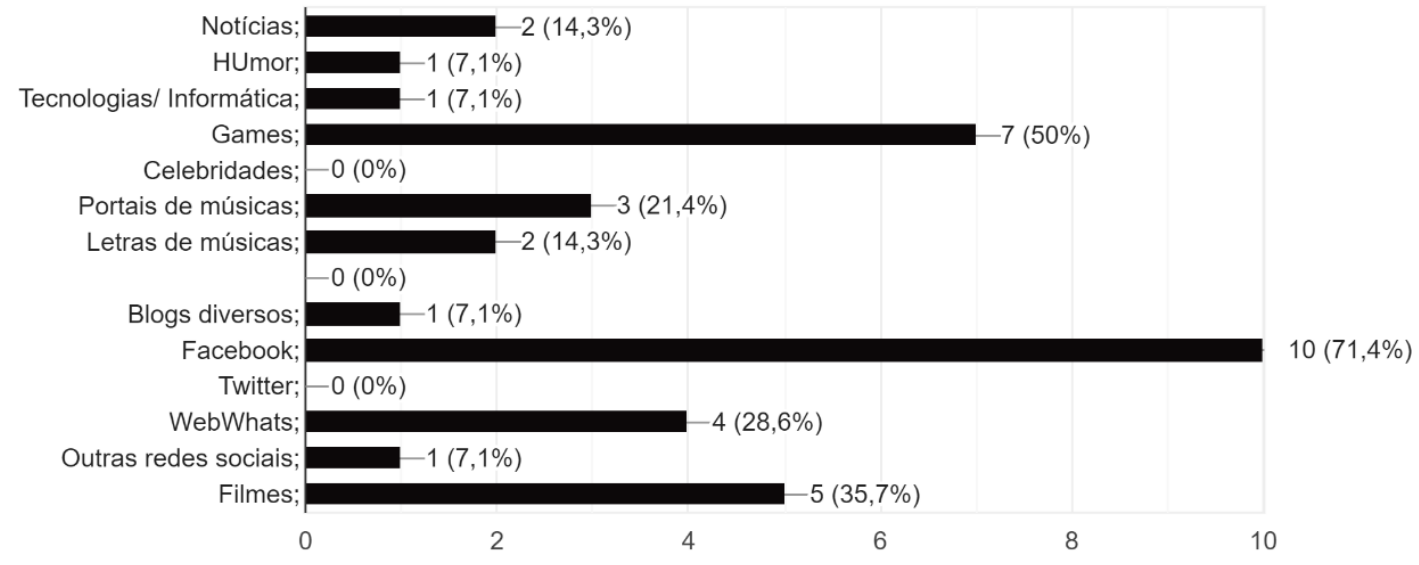

Gráfico 10 - Tipos de websites que os alunos mais acessam. Produzido pela pesquisadora. (2018)

A seguir descrevo as Análises dos dados coletados durante a Intervenção.

Segundo o que já foi mencionado na subseção Contexto, sujeitos e diagnóstico inicial o projeto foi pensado, para ser efetivado com uma turma de $8^{\circ}$ ano, em 2018. Nessa subseção, passo a fazer uma análise dos dados coletados durante as oficinas da intervenção.

Relatando o momento de quando os alunos perceberam que encontrando a sua leitura favorita o momento de ler torna-se prazeroso. Com isso, passando-se a ser encarado não mais como uma obrigação escolar, mas algo sedutor e fascinante, que prende a atenção nos mais variados momentos.

Utilizei as Cadernetas de Metacognição, que segundo DAMIANI (2006), servem para o discente refletir sobre os seus próprios processos de aprender, que compreendeu num pequeno caderno oferecido aos alunos no início das oficinas, este deveria ser usado como instrumento de reflexão ao final de cada oficina.

As Cadernetas de Metacognição se estabelecem como um instrumento de reflexão, foi proposto com a finalidade de registrar, a cada Oficina, as aprendizagens e as dificuldades encontradas pelas estudantes. Nesta proposta, os discentes foram convidados a escrever o que aprenderam, e o que gostariam de aprender após cada encontro da Intervenção. Esse registro tem como desígnio permitir o acompanhamento e a tomada de consciência sobre a aprendizagem. Na Oficina posterior àquele apontado na Caderneta, incide na leitura dos registros. Esse momento tem como finalidade resgatar os tópicos desenvolvidos no encontro anterior. 
A pesquisa apresenta a ideia de que a leitura e a escrita são elementos formativos. Onde a escrita permite o encontro consigo mesmo, rememorar as experiências, a ressignificação da prática, a probabilidade de problematizar e modificar a prática, distinguirse como atividade de auto formação, "Exercitando a reflexão e a escrita, o professor passa a realizar com maior autonomia a análise de seu contexto, o registro e a articulação reflexiva, o que lhes permite avaliar, revisar, ampliar o que faz enquanto docente.” (NÖRNBERG, 2011, p. 04).

No que diz respeito à leitura, ela pode ser considerada como experiência que compartilha conhecimentos e percepções. No contexto da Intervenção, a leitura pode ser considerada como tarefa em que os discentes se colocam e se assumem frente ao grupo, assinalando como atividade de desenvolvimento grupal. Ler é dar significado ao texto escrito. (...) ler não é só transpor imagens gráficas em imagens sonoras, mas sim signos visíveis em sentido (...). A partir do aparecimento da humanidade, o homem lê o mundo que o rodeia entendendo a necessidade de aplicar uma definição por meio das diversas linguagens: gestual, pictórica, oral, escrita. Ser ledor é ser, então, elaborador de significados. (KRAMER, 1997, p. 24). Por meio do redirecionamento de elementos coletados nas ocasiões das Oficinas.

Através da interação dos educandos nas Oficinas, os mesmos realizaram a confecção de Cadernetas de Metacognição onde alunos responderam perguntas em forma de questionário, as duas questões abaixo, onde o contato cotidiano com a leitura, proporcionava a eles formulação de resposta ao conteúdo, em relação as Oficinas desenvolvidas.

O que eu aprendi na aula de hoje?

O que eu gostaria de ter aprendido?

Tais questões foram, por mim adaptadas considerando o método da Caderneta de Metacognição de Damiani (2006), em que os alunos escrevem as suas percepções sobre as temáticas abordadas e por consequência refletem sobre seus registros, e ao concluir cada Oficina os estudantes respondem as perguntas propostas.

Essas duas questões serviram para norteará a escrita da caderneta: O que eu aprendi? O que eu gostaria de aprender? Os alunos eram, portanto, desafiados a refletir criticamente sobre o que haviam aprendido ou não durante cada oficina e explicar claramente como se constituiu tal aprendizado. Essa escrita era desenvolvida após cada oficina, em casa, e lida de maneira espontânea na oficina seguinte para o grupo. No princípio, ocorreu uma oposição no ato de escrever, mas foi perceptível a mudança dos que apresentavam seus registros e classificavam como um bom instrumento para conferir sua própria trajetória, buscando despertar o interesse e incentivando uma maior cooperação entre a turma. 
Prevalecendo desta forma a escrita reflexiva, destacada por Oliveira (1995, p. 154) "o sujeito pode refletir e construir conhecimento explícito e a consciência Metacognitiva, pela possibilidade de verificação do discurso escrito enquanto produto de pensamento, de objetivação da experiência pessoal".

Independente de toda a controvérsia existente em relação a Caderneta de Metacognição, sua contribuição para o fortalecimento da aprendizagem (Figueira, s.d.; Brown, 1992; Wolfs, 2000; Wells, 2001; Ferreira, 2003; Ribeiro, 2003; Santos e Romanowski, 2004; Portilho, 2004) e para o fortalecimento do tipo das relações que podem acontecer entre estudantes e professores tem sido divulgado por inúmeros pesquisadores. De acordo com Figueira (s.d.), [...] verifica-se que os indivíduos com experiências Metacognitivas bem desenvolvidas compreendem os objetivos das tarefas, planificam a sua execução, são capazes de aplicar e alterar, conscientemente, estratégias executivas, bem como avaliar seu próprio processo de execução [...] elemento chave no processo de aprender a aprender (p.14).

Ainda que a aceitação da escrita ganhasse a cada oficina mais seguidores, os registros nas cadernetas compreendiam-se a descrições do que havia acontecido em cada oficina. Considerando que uma escrita descritiva não é apreciada como reflexiva, pois apresenta apenas o registro de algumas oficinas relatados. Assim sendo, para que seja considerada uma escrita reflexiva faz-se necessário ir além de considerar eventos, mas indicar elementos que forneçam justificativas de maneira descritiva para que ocorra, as quais estariam baseados em percepções pessoais, considerando pontos de vilta alternativos (MIZUKAMI, 2006).

$\mathrm{Na}$ oficina do dia doze de novembro de 2018, a aluna X, codinome utilizado para preservar a identidade da estudante, quando foi responder, a questão 1, sobre "O que eu aprendi na aula de hoje?", relatou: “Aprendi que devemos experimentar coisas novas, e que não podemos julgar algo que não podemos julgar algo sem conhecer.”

E sobre a questão "O que eu gostaria de aprender? A aluna $\mathrm{X}$ descreveu como respostas, "Aprender sobre outras leituras."

Verificando, assim, que "a metacognição pode ser entendida como a capacidade chave de que depende a aprendizagem, certamente a mais importante: aprender a aprender" (Valente et al., 1989a, p. 75). É necessário destacar que Caderneta de Metacognição era utilizada também como um instrumento de avaliação para que eu pudesse conferir até que ponto os objetivos de cada oficina estavam sendo alcançados.

Percebi que a Caderneta de Metacognição é um instrumento de supervisão, uma maneira de acompanhar os progressos do aluno; capaz de estimular suas capacidades 
cognitivas, ao mesmo tempo em que oferece referências sobre o desempenho do estudante possibilitando sondar se eles aprenderam o que lhes foi ensinado e, dessa maneira, resolver se é preciso retomar os conceitos trabalhados ou aprofundá-los.

A interação com a leitura, buscou desenvolver algo lúdico, e ao mesmo tempo na linguagem infanto-juvenil, como algo mágico ao mundo dos adolescentes, desta maneira oportunizando uma visão de mundo antes não tidas no mundo destes educandos, as mesmas perguntas formuladas a diferentes textos e leituras, produziram nestes educandos uma nova percepção de aprendizado e conteúdo, e questionamentos que originaram um raciocínio mais aguçado na hora de pensar e organizar suas ideias para as respostas e para escritas de questionamentos.

Deste modo deu-se o contato do educando com a leitura formando um padrão diferenciado de educandos, dentro de uma comunidade, antes empobrecidas de leitores, sem muito envolvimento com o mundo da leitura e da escrita, para alguém que pudesse apaixonarse pela prática cotidiana da leitura, desenvolvendo através dela nova perspectiva da realidade em que viviam, e conhecimento antes favorecendo a uma classe elitista econômica por ter acesso aos mais nobres recursos, estava agora aos acessos de quem antes não tinha o hábito da leitura, por não terem tido oportunidade ou acesso a produção do conhecimentos através da leitura.

Constatei que ocorreram muitos momentos em que as atividades propostas cooperaram para que os discentes participassem ativamente do processo interventivo. No entanto, ocorreram também algumas dificuldades no desenvolver das oficinas, mas nada que pudesse lesionar o fluxo do Projeto. A seguir, apresento as considerações finais do trabalho até aqui exposto.

\section{CONSIDERAÇÕES FINAIS}

O presente relatório crítico reflexivo apresenta como objetivo de descrever a intervenção efetivada realizada com alunos do $8^{\circ}$ ano do Ensino Fundamental II, da Escola Municipal Presidente João Goulart, do Município de Arroio Grande, do Estado do Rio Grande do Sul, a intervenção apresentava como objetivo "Despertar nos alunos, do $8^{\circ}$ ano do Ensino Fundamental II, o gosto pela leitura e pela escrita".

Baseado nisso, no decorrer desse trabalho foram tratados conceitos necessários para a sustentação da proposta aqui exposta, assim como também foram exibidos os passos, implementação e avaliação da intervenção pedagógica.

A proposta de cada aluno encontrar a sua leitura ideal, estimulou a participação efetiva de todos os discentes, estimulando o aprendizado e tornando-o mais significativo. 
Por intermédio do Curso de Mestrado, consegui revisitar minhas práticas, entender que ainda tenho muitos erros, e que estou preparada para me reinventar para que minhas aulas não sejam maçantes, apenas cumprindo o calendário letivo, mas que os discentes se interessem pelas aulas e atividades propostas por mim.

Considerando as ideias relatadas neste trabalho, creio que para pesquisas posteriores faz-se necessário repensar a práxis reflexiva do professor, me incluo, pois é perceptível o quanto cresci depois desse trabalho, considero que é essencial esses momentos de reflexão para que as nossas atividades sejam significativas e prazerosas para os discentes.

\section{REFERÊNCIAS}

ARROYO, M.G. Ofício de mestre-Imagens e auto-imagens. 7.ed. Petrópolis, 2004.

Os educandos, seus direitos e o currículo. In: PRESIDÊNCIA DA REPÚBLICA. Ministério da Educação. Secretaria de Educação Básica. Departamento de Políticas de Educação Infantil e Ensino Fundamental. Indagações sobre currículo. Versão preliminar. Brasília, 2006.

BOGDAN, Robert C. e BIKLEN, Sari K. Investigação qualitativa em educação. Uma introdução à teoria e aos métodos. Tradutores: Maria João Alvarez, Sara Bahia dos Santos e Telmo Mourinho Baptista. Portugal: Porto editora, 1994.

CRUZ, Magna do Carmo Silva; MANZONI, Rosa Maria; SILVA, Adriana M. P. da. Rotinas de alfabetização na perspectiva do letramento: a organização do processo de ensino e de aprendizagem. In: BRASIL. Secretaria de Educação Básica. Diretoria de Apoio à Gestão Educacional. Pacto nacional pela alfabetização na idade certa: caderno a organização do planejamento e da rotina no ciclo de alfabetização na perspectiva do letramento: ano 2: unidade 2. Ministério da Educação, Secretaria de Educação Básica, Diretoria de Apoio à Gestão Educacional. Brasília: MEC, SEB, p. 16-26, 2012b. Disponível em: Acesso em: 11 jun. de 2018.

DAMIANI, Magda Floriana; NEVES, Rita de Araújo. Vygotsky e as teorias da aprendizagem. UNIrevista, vol. 1, n.2, 2006. 
DENSCOMBE, M. (2007) The good research guide: for small-scale social research projects. 3. ed. New York: Open University Press.

GERALDI, João Wanderley (org.). O texto na sala de aula. São Paulo: Ática, 2006 [1984].

FERNANDEZ, Alícia. A mulher escondida na professora: uma leitura psicopedagógica do ser mulher, da corporalidade e da aprendizagem. Porto Alegre: Artes Médicas, 1992.

FOUCAMBERT, Jean. A leitura em questão. Porto Alegre: Artes Médicas, 1994. 157p.

GOldenberG, M. A arte de Pesquisar. Rio de Janeiro- São Paulo. Editora Record, 2004

HATCHUEL, A. Intervention research and the production of knowledge. In: CERF, M (et al.) Cow up a Tree. Knowing and Learning for Change in Agriculture.Case studies from Industrialised Countries. Paris: INRA, p. 55-68, 2000.

LAKATOS, E.M. e MARCONI, M. de A. Fundamentos de metodologia científica - 5. ed. São Paulo : Atlas 2003.

LERNER, Délia. Ler e Escrever na escola: o real, o possível e o necessário. Porto Alegre: Artmed. 2002, 120 p.

LIMA, P. G. O PPP como instrumento do exercício participativo e democrático. 6. In: LIMA, A. B. de. (org.). PPP: participação, gestão e qualidade da educação. Uberlândia: Assis Editora, 2015b, p. 93-113.

LOIS, L. Teoria e prática da formação do leitor: leitura e literatura na sala de aula. Porto Alegre: Artmed, 2010.

LÜDKE, Menga; ANDRÉ, Marli Eliza Dalmazo Afonso de; CRUZ, Giseli Barreto da. Aproximando Universidade e escola de educação básica pela pesquisa. Cadernos de Pesquisa, São Paulo, v. 35, n. 125, p. 81-109, maio/ ago. 2005. 
MARCONI, Marina de Andrade. Fundamentos de Metodologia Científica.5 $5^{\text {a }}$ Ed. São Paulo: Atlas, 2003

MARCUSCHI, Luiz Antônio. Produção textual, análise de gêneros e compreensão. São Paulo: Parábola Editorial, 2008.

MINAYO, Maria Cecília de S. (org.) Pesquisa social. 21 ed. Petrópolis: Vozes, 2002.

MORAN, José Manuel. A educação que desejamos novos desafios e como chegar lá. Campinas: Papirus, 2007.

MORIN, Edgar. Os sete saberes necessários à Educação do Futuro. São Paulo: Cortez, 2000.

RUFINO, Cristiene Silva. MIRANDA, Maria Irene. A contribuição da pesquisa de intervenção para a prática pedagógica. Horizonte Científico, v. 1, n. 1, 2007.

SEAL, Ana Gabriela de Souza. O tratamento da heterogeneidade de conhecimentos dos aprendizes no segundo ano do ciclo de alfabetização. In: BRASIL. Secretaria de Educação Básica. Diretoria de Apoio à Gestão Educacional. Pacto nacional pela alfabetização na idade certa: caderno a heterogeneidade em sala de aula e os direitos de aprendizagem no ciclo de alfabetização: ano 2, unidade 7. Ministério da Educação, Secretaria de Educação Básica, Diretoria de Apoio à Gestão Educacional. Brasília: MEC, SEB, p. 16-26, 2012. Disponível em: Acesso em: 11 de jun. 2018.

TRIVIÑOS, Augusto Nilbaldo da Silva (Org) e NETO, Vicente Molina. A pesquisa qualitativa na Educação Física: Alternativas metodológicas. Porto Alegre: Ed.Universidade /UFRGS/Sulina, 1999.

VIGOTSKI, L. S. A formação social da mente. 6. ed. São Paulo: Martins Fontes, 1998. 
RELACult - Revista Latino-Americana de Estudos em Cultura e Sociedade

Revista Latinoamericana de Estudios en Cultura y Sociedad | Latin American Journal of Studies in Culture and Society V. 06, Edição Especial, out., 2020, artigo no 1878| claec.org/relacult | e-ISSN: 2525-7870 